\title{
Lamprey Neurofilaments Combine in One Subunit the Features of Each Mammalian NF Triplet Protein But Are Highly Phosphorylated Only in Large Axons
}

\author{
Samuel J. Pleasure, ${ }^{1}$ Michael E. Selzer, ${ }^{2}$ and Virginia M.-Y. Lee ${ }^{3}$ \\ 1The David Mahoney Institute of Neurological Sciences, ${ }^{2}$ The Department of Neurology, and ${ }^{3}$ The Department of \\ Pathology and Laboratory Medicine (Neuropathology), The University of Pennsylvania School of Medicine, Philadelphia, \\ Pennsylvania 19104
}

\begin{abstract}
Compared with heteropolymeric assemblies of neurofilament (NF) triplet proteins in mammalian NFs, lamprey (Petromyzon marinus) NFs are homopolymers of $180 \mathrm{kDa}$ subunits (NF180). We describe unique features of lamprey NF 180 that distinguish it as a prototype of vertebrate NF subunits. These features may underlie key functions subserved by the earliest vertebrate NFs.

Lamprey NF 180 displays properties common to all intermediate filament (IF) proteins, but it also exhibits features that distinguish the mammalian triplet of NF subunits from all other IF proteins. For example, digestion of lamprey NF180 with chymotrypsin produces an insoluble $40 \mathrm{kDa}$ core unit and releases a soluble fragment intermediate in size (140 kDa) to the carboxy-terminal (sidearm) extensions of the 2 high-molecular-weight $\left(\boldsymbol{M}_{r}\right)$ mammalian NF subunits. The core unit contains epitopes similar to those in the core of each mammalian NF triplet protein, while the soluble fragment contains other determinants similar to those in the sidearms of the 2 high- $M$, mammalian NF polypeptides. Like these polypeptides, the immunological properties of some NF 180 peripheral determinants were strongly affected by their phosphorylation state. Indeed, NF180 shares immunological similarities with the multiphosphorylation repeat domains in the high- $\boldsymbol{M}_{r}$ mammalian NF subunits. Further similarities with mammalian NF proteins include the preferential expression of poorly phosphorylated NF 180 isoforms and of phosphatedependent NF180 epitopes in axons of all sizes, and the restriction of nonphosphorylated NF 180 isoforms to neuronal perikarya. In marked contrast to mammals, however, the most heavily phosphorylated isoforms of NF180 were expressed exclusively in large-diameter axons.
\end{abstract}

We conclude that the single subunit forming lamprey NFs exhibits the essential features of mammalian NFs, i.e., a filament-forming core and a carboxy-terminal extension with a multiphosphorylation site. Further, the sharp restriction of heavily phosphorylated NF 180 to large axons suggests that

\footnotetext{
Received May 31, 1988; revised July 28, 1988; accepted July 29, 1988.

We thank Drs. M. M. Black, M. J. Carden, J. Kamholz, and J. Q. Trojanowski, who offered helpful comments on the manuscript; Mr. E. Clark and Mr. M. Memmo for expert technical assistance; and Mr. Joseph Snedeker for providing the electron micrographs. This work was supported in part by NIH Grants NS18616 and NS-14837. Mr. Samuel Pleasure is the recipient of a MSTP Predoctoral Fellowship from the NIH.

Correspondence should be addressed to Dr. Virginia M.-Y. Lee at the above address.

Copyright (C) 1989 Society for Neuroscience $0270-6474 / 89 / 020698-12 \$ 02.00 / 0$
}

multiphosphorylation domains were acquired during evolution to permit larger axon diameters and faster conduction velocities.

For as yet unknown reasons, mammals have evolved at least 5 cell-type specific classes of intermediate filaments (IFs), including a neuron-specific class referred to as neurofilaments (NFs). Non-neuronal mammalian IFs exist as homopolymers or heteropolymers of 1 or 2 different subunits, but mammalian NFs are heteropolymers of a triplet of proteins, i.e., a low-, middle-, and high-molecular-weight $\left(M_{r}\right)$ subunits NF-L, NF-M, and NF-H, respectively), which in rat have an apparent $M_{r}$ of 70 , 145 , and $200 \mathrm{kDa}$, respectively (see Schlaepfer, 1987, for a recent review). NFs are present in functionally distinct regions (axon, dendrite, soma) of many different neurons (Peters et al., 1976), but their precise function(s) is largely enigmatic. However, in larger axons, the number of NFs correlates with axon diameter (e.g., Friede and Samorajski, 1970), and this, together with other elegant experimental data, suggests that the number of NF's regulate the diameter of some populations of large axons (Hoffman et al., 1984, 1987).

A key structural feature of all IF subunits is a highly conserved $40 \mathrm{kDa} \alpha$-helical coiled-coil core required for the self-assembly of IF subunits into 8-10 nm filaments (see Steinert et al., 1985, for a recent review). In mammalian NF subunits, the $40 \mathrm{kDa}$ core is flanked by a $10 \mathrm{kDa}$ extension at the amino-terminus and by a peripheral domain or sidearm of variable length at the carboxy-terminus, which accounts for differences in the $M_{r}$ of NF subunits (Chin et al., 1983; Geisler et al., 1983). The sidearms of NF-M and NF-H are extensively phosphorylated (up to $50 \mathrm{~mol}$ phosphate/mol protein) (Julien and Mushynski, 1982, 1983; Carden et al., 1985). These phosphate residues cluster into tandem repeats or multiphosphorylation domains and appear to be present in NF-H of almost all higher vertebrates (Lee et al., 1986a, 1988b; Geisler et al., 1987). Similar repeats are also found in NF-M of human (Geisler et al., 1987; Myers et al., 1987; Lee et al., 1988a) and chicken (Zopfs et al., 1987; Lee et al., 1988a), but not in NF-M of rat (Napolitano et al., 1987) and mouse (Levy et al., 1987). Since multiple tandem phosphate sites appear to distinguish NFs from all other classes of IFs, these sites in the $\mathrm{COOH}$-terminal peripheral domains may be oriented: $\supset$ as to regulate the interactions of NFs with each other and with neighboring organelles.

The somatofugal gradient of mammalian NF-H and NF-M phosphorylation (Sternberger and Sternberger, 1983; Lee et al., 
1987) and its early emergence in embryonic neurons (Carden et al., 1987) suggest that phosphorylation may mediate dynamic axon-specific functions of mammalian NFs. However, the complexity of the mammalian nervous system and the plethora of differentially phosphorylated NF-H and NF-M isoforms have made it difficult to determine precisely how phosphorylation might mediate axon-specific NF functions in mammalian systems.

For these reasons, we undertook to elucidate the functional implications of NF phosphorylation in a simple vertebrate nervous system. We chose the lamprey for this purpose because it is the most primitive vertebrate (Hardisty, 1982). Lamprey NFs are known to be homopolymeric IFs built from assemblies of single $180 \mathrm{kDa}$ (NF180) subunits (Lasek et al., 1985; Pleasure et al., 1986). Further, the lamprey has a relatively simple CNS comprised exclusively of unmyelinated axons of variable diameter (Rovaincn, 1979). Howcver, the utility of the lamprey for studies of NF function depends critically on the relationship of lamprey NF180 to mammalian NF triplet proteins. Accordingly, our experimental design included a thorough characterization of lamprey NF180, in addition to an assessment of the functional significance of its phosphorylation states.

\section{Materials and Methods}

Purification of enriched NF preparations from lamprey and rat. NF enriched cytoskeletal preparations were obtained from lamprey spinal cords following procedures described previously for the preparation of mammalian cytoskeletal fractions (Lee et al., 1987). Briefly, larval sea lampreys (7-10 cm long) were anesthetized in $0.01 \%$ tricaine methane sulfonate and their spinal cords were dissected. Spinal cords (12-20 mg wet weight/cord) were homogenized in buffer ( $20 \mathrm{mg}$ wet weight $/ \mathrm{ml}$ buffer) that contained $1 \%$ Triton $\mathrm{X}-100,0.6 \mathrm{M} \mathrm{KCl}, 2 \mathrm{~mm}$ EDTA, and $2 \mathrm{~mm}$ EGTA in $50 \mathrm{~mm}$ Tris $\mathrm{HCl}$ at $\mathrm{pH} 7.0$. Preliminary studies showed extensive degradation of lamprey NFs if $\mathrm{Ca}^{2+}$ was present in the homogenization buffer. After centrifugation at $100,000 \times g$ for 20 min in a Beckman airfuge, the pellet was dissolved in BUST ( $2 \%$ $\beta$-mercaptoethanol, $8 \mathrm{~m}$ Urea, $1 \% \mathrm{SDS}$, and $0.125 \mathrm{~m}$ Tris $\mathrm{HCl}, \mathrm{pH} 6.8$ ) at a concentration of $5 \overline{\mathrm{mg}}$ (original wet weight) per milliliter of BUST. Homogenates of lamprey spinal cord and brain also were prepared by direct homogenization of nervous tissues in BUST or isoelectric focusing (IEF) sample buffer ( $5 \mathrm{mg}$ wet weight $/ \mathrm{ml}$ ) for 1 - or 2 -dimensional gel electrophoresis, respectively (see below). Enriched rat NF preparations were prepared according to a procedure developed previously (Lee et al., 1987).

Preparation of monoclonal antibodies. The initial production and charactcrization of the monoclonal antibodies (mAbs) used in this study are detailed elsewhere (Carden et al., 1985; Lee et al., 1986a, b, 1987). These mAbs were raised using gel-purified rat or bovine NF subunits as immunogens. The specificity of these anti-NF mAbs for lamprey NF1 80 was determined by immunochemical and immunohistochemical methods exactly as described earlier (Carden et al., 1985; Lee et al., $1986 \mathrm{a}, \mathrm{b}, 1987$ ) except that lamprey tissues or tissue homogenates were used as test substrates. For the studies described here, we selected only those mAbs that cross-reacted with lamprey NF180 in immunoblots as well as in immunohistochemical preparations. Efforts to probe the IFs of CNS supporting cells (glial cells) for comparison with NF180 using an $\mathrm{mAb}$ raised to bovine glial filament protein (Lee et al., 1984) were unsuccessful because this $\mathrm{mAb}(2.2 \mathrm{~B} 10)$ failed to cross-react with any lamprey proteins in immunoblots and it did not bind to any structures in immunohistochemical preparations of lamprey tissucs.

One- and two-dimensional SDS-PAGE and immunoblots. For 1-dimensional (1-D) analysis by SDS-PAGE, proteins were separated on 0.75 -mm-thick $7.5 \%$ polyacrylamide gels. For 2-dimensional (2-D) gel analysis, IEF was used in the first dimension and SDS-PAGE in the second dimension exactly as described previously (Lee et al., 1987). For IEF, a pH gradient of 4.5-8.0 was achieved using LKB ampholines ( $\mathrm{pH}$ $3.5-10,5.0-7.0$, and $4.0-6.0$ ) in a ratio of $2: 9: 9$ at a final concentration of $2 \%$. Gels (1-D and 2-D) were stained with Coomasie G-250 or the Gelcode silver stain kit (Pierce Chemicals). Proteins separated in 1-D and 2-D gels were transferred electrophoretically to sheets of nitrocel- lulose paper, and the proteins in these gel replicas were probed with $\mathrm{mAbs}$ by the peroxidase-antiperoxidase (PAP) method as described (Lee et al., 1987).

Chymotryptic digestion of lamprey NF180. Lamprey NFs were digested with chymotrypsin according to a modification of previously described procedure (Carden et al., 1985). Briefly, lamprey spinal cord samples (10 mg tissue/ml buffer) were homogenized in Tris buffered saline (TBS) containing $2 \mathrm{~mm}$ EGTA, $1 \mathrm{~mm}$ EDTA, and $0.1 \mathrm{unit} / \mathrm{ml}$ aprotinin. The homogenate was centrifuged in an airfuge $\left(1 \times 10^{5} \mathrm{~g}\right)$ at $4^{\circ} \mathrm{C}$ for $1 \mathrm{hr}$, after which the pellet was resuspended in TBS. Aliquots of the resuspended pellet were incubated with different concentrations of chymotrypsin at $22^{\circ} \mathrm{C}$ for $30 \mathrm{~min}$ and the reaction stopped by addition of phenylmethylsulfonyl fluoride (PMSF) to a concentration of $5 \mathrm{~mm}$. Samples were centrifuged to separate pelletable fragments from soluble proteins in the supernatant. Each fraction was mixed separatcly with sample buffer (Laemmli, 1970), boiled, and subjected to SDS-PAGE. Proteins in these gels were stained with Coomasie blue or analyzed by the immunoblot method as described above.

Immunohistochemistry. PAP immunohistochemistry was performed on $10-\mu \mathrm{m}$-thick deparaffinized sections cut from paraffin embedded tissue that was immersion fixed as 4- to 6-mm-thick blocks in Bouin's solution for 6-12 hr. These procedures and the controls used in these experiments have been described (Lee et al., 1986a).

Enzymatic dephosphorylation of tissue sections and isolated lamprey $N F s$. Tissue sections were enzymatically dephosphorylated by incubation for $3 \mathrm{hr}$ at $37^{\circ} \mathrm{C}$ with $10-40$ units $/ \mathrm{ml}$ of $E$. coli alkaline phosphatase (Sigma type III-N) followed by PAP immunohistochemistry. The procedures and controls for these experiments have been described (Lee et al., 1986a). NF-enriched lamprcy spinal cord preparations (at a concentration of about $0.5 \mathrm{mg} / \mathrm{ml}$ ) were dephosphorylated in a similar manner, and the reaction was stopped by adding excess phosphate buffer (Carden et al., 1985; Lee et al., 1986a).

Electron microscopy. Representative samples of lamprey spinal cord were excised in Ringer's solution, immersion fixed in buffered glutaraldehyde $(2 \%)$ for $2 \mathrm{hr}$, rinsed in Ringer's, and prepared by standard procedures for examination by routine transmission microscopy (Phillips 201).

\section{Results}

Biochemical and immunochemical properties of the lamprey $180 \mathrm{kDa}$ cytoskeletal protein place it in the family of IF proteins

Figure $1 A$ shows the protein composition of total homogenates and Triton $\mathrm{X}$-100-insoluble cytoskeletal-enriched fractions from lamprey spinal cord separated by SDS-PAGE. Several protein bands, including the apparent $M_{r} 180 \mathrm{kDa}$ single lamprey NF subunit intially described by Lasek et al. (1985), were found to be enriched in cytoskeletal preparations (compare lanes 3 and 5 in Fig. $1 A$ ). As noted in a number of mammalian systems, relative insolubility in Triton $\mathrm{X}$-100-containing solutions is a characteristic property of NF subunits, as well as of other cytoskeletal proteins of the CNS (Schlaepfer, 1987). That intraaxonal $8-10 \mathrm{~nm}$ IF's are indeed abundant in lamprey spinal cord is well illustrated in Figure $1 B$. Note that orderly arrays of NFs are distributed throughout the cross-sectional area of unmyelinated axons. NFs are the dominant cytoskeletal structure in largediameter axons, where they are infrequently interspersed with other organelles (e.g., microtubules). Furthermore, like their mammalian counterparts, lamprey NFs exhibited readily identifiable 1 - to 2-nm-thick, straight, and relatively smooth sidearms varying in length from 30 to about $90 \mathrm{~nm}$ (insert in Fig. $1 B)$. Some sidearms extended from one NF to another, others extended from an NF to another structure (e.g., a microtubule or the internal surface of the axolemma), and yet others did not abut any other organelles, although they were attached at one end to an NF (Fig. $1 B$ and insert). Notably, glial processes also contained numerous 8- to 10-nm-diameter, tightly packed, smooth IFs without lateral projections, and they presumably 

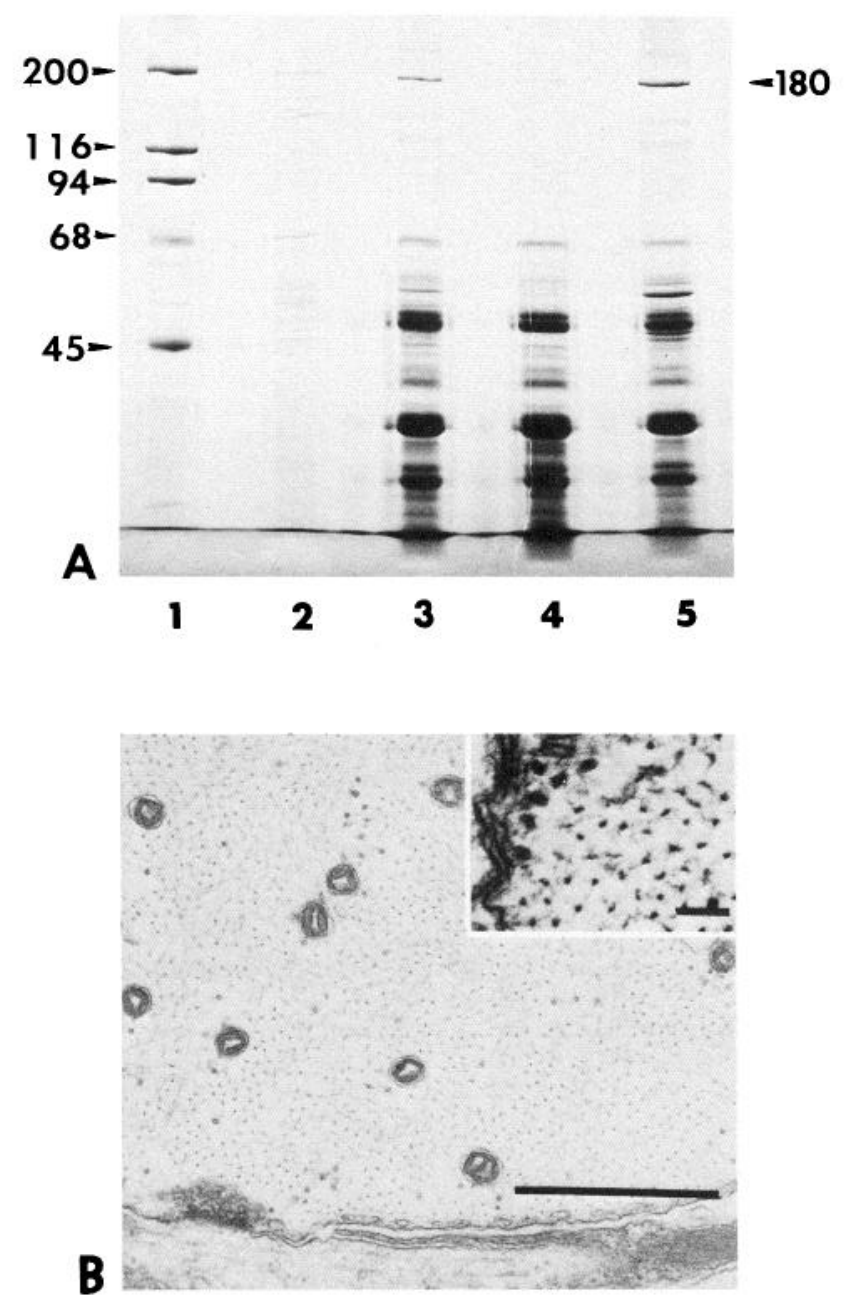

Figure 1. A, The 1-D SDS-PAGE (7.5\%) profile of lamprey spinal cord proteins as compared with molecular markers (lane 1 with $M_{r}$ in $\mathrm{kDa}$ at left) and rat spinal cord NF proteins (lane 2). A whole homogenate (lane 3) of lamprey spinal cord, and a Triton X-100-soluble (lane 4) versus a Triton X-100-insoluble cytoskeletal enriched fraction (lane 5) of lamprey spinal cords reveals a protein designated as NF180 (see hash mark and $M_{r}$ at right) only in the whole homogenate and Triton $\mathrm{X}-100$-insoluble fraction. $B$, Low-power electron micrograph of a cross section of an axon in lamprey spinal cord (scale bar, $1 \mu \mathrm{m}$ ). The numerous $10 \mathrm{~nm}$ filaments in $B$ are seen at higher magnification in the insert (scale bar, $100 \mathrm{~nm}$ ), and at this power, 1-2 nm inter-NF "cross bridges" are seen.

represent an early. vertebrate form of glial filaments (data not shown).

Immunological evidence that the lamprey $180 \mathrm{kDa}$ cytoskeletal protein is closely related to other members of the IF family of proteins is provided in Figure $2 A$, which shows that this polypeptide is recognized in 2-D nitrocellulose replicas by the anti-IFA mAb (Pruss et al., 1981). Extensive studies have shown that this $\mathrm{mAb}$ binds to a highly specific IF epitope shared by all IF proteins (Magin et al., 1987). The anti-IFA mAb detected a streak at $M_{r} 180 \mathrm{kDa}$ in addition to several spots between $M_{r}$ $50-60 \mathrm{kDa}$ (Fig. $2 A$ ). Thus, the $180 \mathrm{kDa}$ protein clearly belongs to the IF family of proteins, and the streak like profile of this $180 \mathrm{kDa}$ immunoband in the 2-D gel replica suggests that this protein is a high- $M_{r}$ NF subunit since such behavior on 2-D gels is characteristic of mammalian NF-H (Lee et al., 1987; Nixon et al., 1987; Oblinger, 1987). Further, the low affinity of

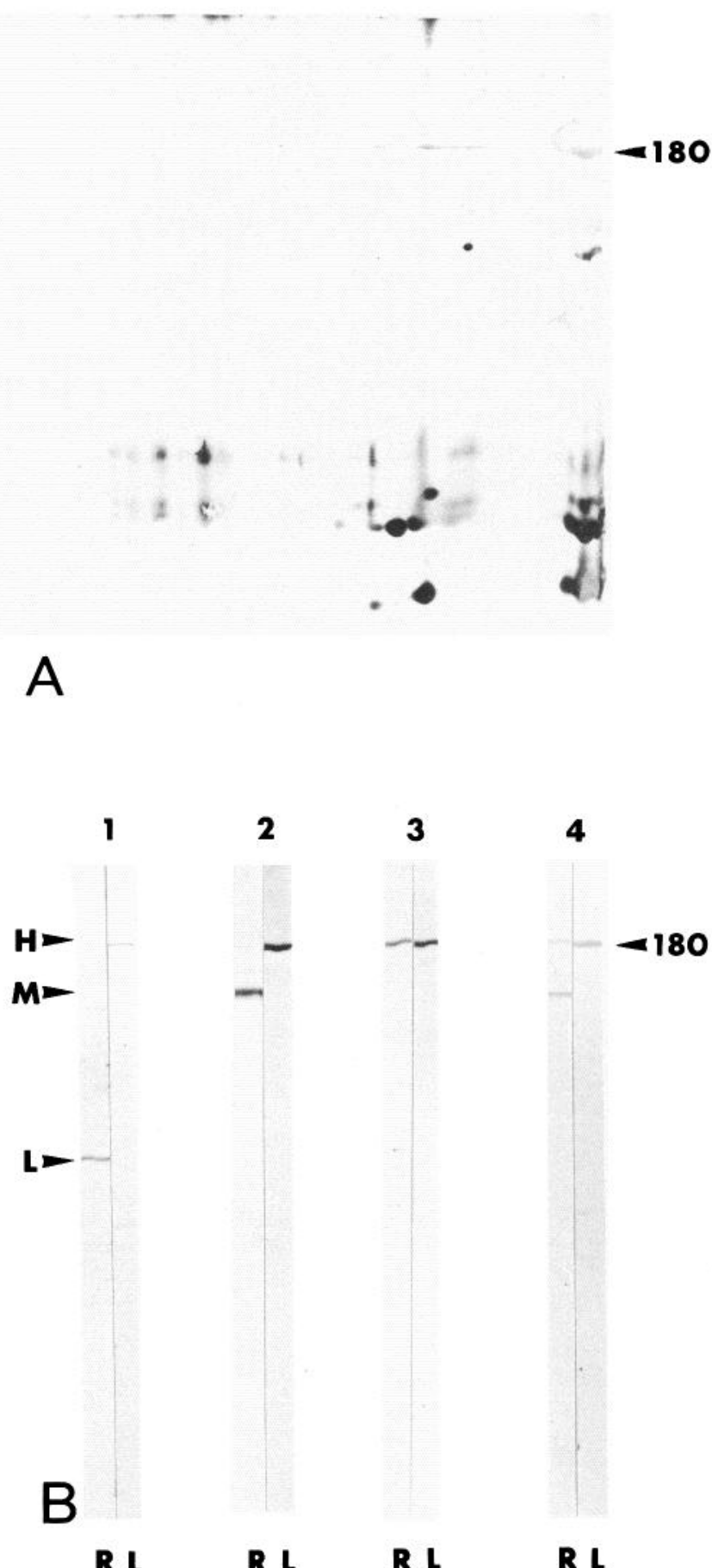

\section{$\begin{array}{llll}\mathbf{R} \text { L } & \mathbf{R} \text { L } & \mathbf{R} \text { L } & \text { R L }\end{array}$}

Figure 2. A, Immunoblot produced from a 2-D gel used to separate proteins in a whole homogenate of lamprey spinal cord and probed with the anti-IFA mAb (Pruss et al., 1981). In addition to NF180 (hash mark with $M_{r}$ indicated), anti-IFA stained several spots between $45-50 \mathrm{kDa}$ that might represent non-neuronal (e.g., glial and/or vimentin filament) IF proteins. $B$, Rat and lamprey spinal cord NF preparations separated by 1-D SDS-PAGE (7.5\%) and then transferred to nitrocellulose paper. Identical strips were cut from the rat $(R)$ and lamprey $(L)$ nitrocellulose replicas and incubated as pairs ( 4 in all here) with different $m A b s$. From left to right, the mAbs used with each pair were Sd112, RMO14, RMO125, and RMO205, respectively. Note that mAbs specific for each rat NF triplet protein (identified as $H, M$, and $L$ at left) are capable of crossreacting with lamprey $\operatorname{NF} 180\left(M_{r}\right.$ indicated to the right $)$. 
anti-IFA for this $180 \mathrm{kDa}$ lamprey protein is reminiscent of its poor immunoreactivity for the higher- $M_{r}$ squid NF subunits (Cohen et al., 1987). The spots between $M_{r} 50-60 \mathrm{kDa}$ are probably non-neuronal IFs, as similarly described recently in Myxicola (Bartnik et al., 1987) and keratin spots that frequently contaminate acrylamide preparations.

This putative relationship of the $180 \mathrm{kDa}$ lamprey polypeptide to IF proteins, and particularly to 1 of the 3 mammalian NF triplet proteins, was reinforced by the failure of $\mathrm{mAb}$ raised to mammalian glial filament and vimentin filament proteins (Lee et al., 1984) to detect the lamprey $180 \mathrm{kDa}$ polypeptide in immunoblot assays (data not shown), while many anti-rat NF protein mAbs did bind lamprey NF180. For example, $4 \mathrm{mAbs}$ raised to rat NF subunit proteins that were found previously to be specific for rat NF-L, NF-M, NF-H, and epitopes shared by NF-M and NF-H, respectively (Lee et al., 1987) all intensely slained lamprey NF180 in nitrocelluluse replicas of 1-D SDSPAGE gels containing cytoskeletal lamprey spinal cord preparations. Since, as shown in Figure $2 B$, all $4 \mathrm{mAbs}$ selectively recognized the $180 \mathrm{kDa}$ polypeptide from lamprey spinal cord and no other proteins, it is reasonable to assume that this protein is immunologically related to the 3 mammalian NF triplet proteins. Accordingly, we refer to it throughout the remainder of this paper as the lamprey NF180 subunit, or simply NF180.

\section{Lamprey NF180 shares extensive immunological properties with each mammalian NF triplet protein}

We assessed the extent of the immunological similarities between lamprey NF1 80 and other mammalian (especially rodent) NF triplet proteins using a large panel of $\mathrm{mAbs}$ previously raised to rat or bovine NF subunits by characterizing the epitopes in lamprey NF1 80 that were recognized by these mAbs. The immunochemical and immunohistochemical propertics of these mAbs have been characterized extensively using a diverse array of NF proteins or tissues from a variety of mammalian (including rodent) and submammalian species (Carden et al., 1985; Lee et al., 1986a, b, 1987, 1988a, b). Briefly, in the rodent, where they have been examined most thoroughly, these mAbs have the ability to distinguish: (1) NFs in different states of phosphorylation, i.e., nonphosphorylated, or poorly phosphorylated $(\mathrm{P}[-]) \mathrm{NF}$ protein isoforms, and a large number of $\mathrm{NF}$ protein variants that exist in low $(\mathrm{P}[+])$, intermediate $(\mathrm{P}[++])$ and heavily $(\mathrm{P}[+++])$ phosphorylated forms; $(2)$ epitopes in different core and peripheral domains of individual NF subunits; (3) NF determinants in core and peripheral domains that are immunologically phosphate independent (P[ind]), i.e., unaffected by the state of phosphorylation of NF-M and NF-H peripheral regions. Additionally, many of the mAbs from these 3 groups were shown to recognize the multiphosphorylation repeat domains present in the $\mathrm{COOH}$-terminal regions of either human NF-M (Lee et al., 1988a) or rat NF-H (Lee et al., 1988b). Finally, the immunochemical properties of these $m$ Abs correlate closely with their immunohistochemical staining patterns in rat and other species such that a somatofugal gradient of increasing degrees of phosphorylation can be detected in CNS neurons (Carden et al., 1987; Lee et al., 1987; Schmidt et al., 1987).

Table 1 summarizes the mAbs in our large library of anti-NF antibodies (the specificities of these $\mathrm{mAhs}$ for a wide variety of biochemically and spatially distinct rat NF triplet protein determinants are shown in the left-hand column) that also have the ability to bind the lamprey NF180 subunit. Figure 3 is a schematic representation of the possible binding domains along

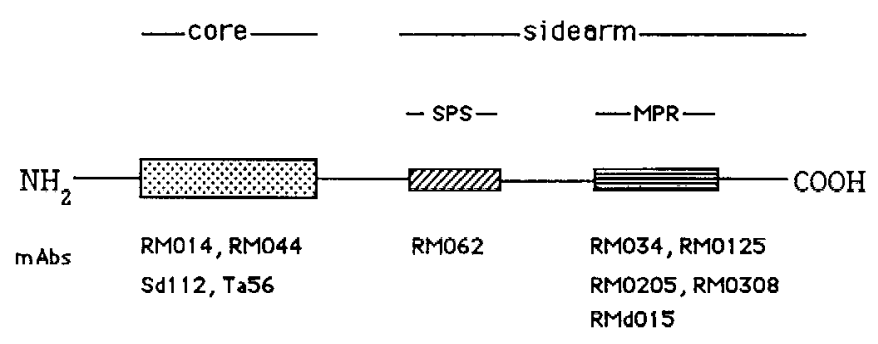

SPS=structural phesphorylation site

$M \bar{P} \bar{R}=$ multiple phosphorylation repeat

Figure 3. Highly schematic representation of the lamprey NF180 protein and the putative structural/functional domains within it to show the probable sites in which epitopes are located to which the mAbs used in this study bind. The schematic is a conceptual model of the protein, rather than an actual map of the protein based on known sequence information. The amino-terminus $\left(\mathrm{NH}_{2}\right)$ and carboxy-terminus $(\mathrm{COOH})$ are shown. The core region is indicated by the stippled box; the diagonally barred box represents the obligatory phosphorylation region in the peripheral domain, which probably subserves a structural function; the horizontally barred box refers to the multiphosphorylation repeat region in the peripheral domain, which may subserve dynamic functions as a result of cycles of phosphorylation and dephosphorylation. The proximity of SPS to the core and the remoteness of MPR from the core are conjectural al this time.

NF180 of some of our mAbs. Of approximately 160 anti-NF mAbs tested initially by $1-\mathrm{D}$ immunoblot analysis, 31 detected lamprey NF180. Because the lamprey NF180 subunit was detected by at least one mAb that is specific for an epitope in the core domain of each rat NF subunit, these data imply that lamprey NF180 has a core domain which is immunologically similar to the core region of each rat NF triplet protein. Thus, despite having an $M_{r}$ of $180 \mathrm{kDa}$, which is intermediate between that of rat NF-M (145 kDa) and NF-H (200 kDa), lamprey NF1 80 has a core domain which shares significant immunological properties with all three rat NF subunits, including rat NF-L (70 kDa).

Additional observations served to solidify the strong immunological relationship of lamprey NF180 to mammalian NF-M and NF-H. For example, lamprey NF180 also was detected by one or more $\mathrm{mAbs}$ from each of 3 major $\mathrm{mAb}$ categories described earlier, and many of these mAbs were of the class that bind to phosphorylation-state-specific epitopes in the peripheral domains of rat NF-M and/or NF-H. Notably, over half $(11 / 19)$ of the sidearm-specific anti-rat NF mAbs that crossreacted with lamprey NF180 recognize the human NF-M and/ or rat NF-H multiphosphorylation repeat regions in various states of phosphorylation (Lee et al., 1988a, b). Additionally, one of these cross-reactive mAbs has also been shown to recognize a linear NF-M and -H sequence of just 4 amino acids, i.e., $\mathrm{KSP}(\mathrm{V} / \mathrm{A})$, in its nonphosphorylated form. These data alone are highly consistent with the hypothesis that lamprey NF180 includes a long peripheral sidearm that is immunologically quite similar to the sidearms of mammalian NF-M and NF-H. Furthcr, thcy also suggest that a multiphosphorylation repeat region within the lamprey NF1 80 sidearm may exist and may be functionally similar to immunologically homologous repeats in NF-M and/or NF-H of mammals. Finally, the sequence KSP(V/A) is a candidate building block for the multiphosphorylation repeat in lamprey NF180, as appears to be the case for mammalian NF-M and NF-H (Lee et al., 1988a, b). 
Table 1. Properties of the $>160$ anti-rat NF subunit specific mAbs tested for their ability to cross-react with lamprey NF180

\begin{tabular}{cll}
$\begin{array}{l}\text { Specificity of } \\
\text { mAbs in rat }\end{array}$ & $\begin{array}{l}\text { Number of } \\
\text { mAbs reactive } \\
\text { with NF180 }\end{array}$ & $\begin{array}{l}\text { Representative } \\
\text { mAbs used here }\end{array}$ \\
\hline $\begin{array}{l}\text { NF-L } \\
\text { P[ind]-core }\end{array}$ & 3 & Sdl12 \\
$\begin{array}{l}\text { NF-M } \\
\text { P[+] }\end{array}$ & & RMO62 \\
P[+++] & 2 & none \\
P[ind]-sidearm & 0 & RMO308 \\
P[ind]-core & $7^{a}$ & RMO14, RMO44 \\
NF-H & 8 & \\
P[+] & & RMO224 \\
P[+++] & 1 & RMO34 \\
P[-] & $3^{b}$ & RMd09 \\
P[ind]-sidearm & $2^{c}$ & RMO125 \\
P[ind]-core & $1^{d}$ & Ta56 \\
NF-M \& NF-H & 1 & \\
P[-] & & RMdO15 \\
P[ind]-sidearm & $1^{e}$ & RMO205
\end{tabular}

The characteristics of the epitopes recognized by 31 of these mAbs in rat NF-L, NF-M, NF-H, or NF-M and NF-H are listed in the left-hand column. The designations $\mathrm{P}[+], \mathrm{P}[+++], \mathrm{P}[-]$, $\mathrm{P}[$ ind $]$-core, or $\mathrm{P}[$ ind $]$-sidearm are defined in the text. Of the mAbs tested, 31 cross-reacted with lamprey NF 180 and the number of mAbs from each category in the left-hand column is shown in the middle column. Examples of an $\mathrm{mAb}$ from each category are listed in the right-hand column. Superscripts identify NF180 cross-reactive mAbs that bind mammalian multiphosphorylation repeats in NF-M and/or NF-H as follows; $a, 4$ of these mAbs detected a $\mathrm{P}$ [ind] epitope in the multiphosphorylation repeat region of human NF-M; $b, 3 \mathrm{mAbs}$ bind phosphorylation-dependent cpitopes in the multiphosphorylation repeat domain of rat $\mathrm{NF}-\mathrm{H} ; c, 2 \mathrm{mAbs}$ bind dephosphorylation-dependent epitopes in the multiphosphorylation repeat domains of rat NF- $\mathrm{H} ; d$, a single $\mathrm{mAb}$ detects a $\mathrm{P}[\mathrm{ind}]$ epitope in the multiphosphorylation repeat domain of rat $\mathrm{NF}-\mathrm{H}$; $e$, this mAb recognizes the sequence $\mathrm{KSP}(\mathrm{V} / \mathrm{A})$.

\section{Evidence that lamprey NF180 includes a core and a peripheral domain}

To determine whether or not lamprey NF180 contains 2 structurally distinct regions, i.e., an $\alpha$-helical coiled-coil core region and a peripheral sidearm with multiple phosphorylation sites, like those found in mammalian NF-M and NF-H, lamprey NF 180 was analyzed by Coomasie-stained gels and probed with $\mathrm{mAbs}$ in immunoblots following stepwise digestion with chymotrypsin. Under well-controlled conditions, this protease cleaves mammalian NFs and releases the soluble peripheral domains from each mammalian NF subunit without destroying the integrity of the $10 \mathrm{~nm}$ filament backbone that contains the insoluble core domain of each NF subunit (Chin et al., 1983; Carden et al., 1985).

Representative data from these studies are shown in Figure $4 \mathrm{~A}$. At low concentration of chymotrypsin, the bulk of NF180 still sedimented (see lanes $1^{\prime}$ and $2^{\prime}$ in Fig. $4 A$ ), although 3 bands $\left(M_{r} 180,178\right.$, and $\left.140 \mathrm{kDa}\right)$ could be seen in the supernatant as a result of this treatment (Fig. $4 A$, lane $2^{\prime}$ ). The 180 and 178 $\mathrm{kDa}$ bands that were released into the supernatant may have arisen due to slight proteolytic clipping of the amino-terminus, which has been observed for mammalian NF-M (Lce et al., 1987), while the $140 \mathrm{kDa}$ band may represent nearly the entire lamprey NF180 carboxy-terminal or peripheral domain minus the relatively less soluble $40 \mathrm{kDa}$ core region. The release of these bands into the supernatant, especially after treatments with higher concentrations of chymotrypsin, was accompanied by the appearance of fragments having an $M_{r} 40-60 \mathrm{kDa}$ (lanes $1-3$, Fig. 4A) in the pellet fraction. Higher concentrations of chymotrypsin released more of the soluble fragments and also generated a cascade of slightly smaller products with apparent $M_{r}$ of 140,000-110,000 (Fig. 4A, lane $4^{\prime}$ ).

Nitrocellulose replicas of gels similar to those shown in Figure $4 A$ were probed with a number of anti-rat NF mAbs that crossreacted with lamprey NF180 (Fig. 4, $B-D$ ). A mammalian NF-H core-specific mAb (Ta56) detected the 40-60 kDa pelletable fragments but not the 140-110 kDa soluble fragments of lamprey NF1 80 (Fig. $4 B$ ), as found for similarly digested rat NF-H (Lee et al., 1986a). Ta56 appeared to bind to core fragments of NF180 with higher affinity than the intact or partly degraded NF180 (compare the lamprey NF180 standard and lane 1 in Fig. $4 B$ ). Nearly identical results also were obtained using the anti-IFA mAb (data not shown). A PL+] rat NF-M sidearm $\mathrm{mAb}(\mathrm{RMO62})$ and another mAb (RMO125) for a P[ind] epitope in the rat NF-H multiphosphorylation repeat region (Lec et al., 1988b) stained a doublet at $180 \mathrm{kDa}$ and $140-110 \mathrm{kDa}$ bands in the supernatant after extensive digestion (lanes 3 and $4^{\prime}$ in Fig. 4, $C, D$ ). Neither mAb detected the $40-60 \mathrm{kDa}$ bands in the pellet. These results provide additional evidence for the notion that lamprey NF180 may comprise a core and a peripheral region just like mammalian high- $M_{r}$ NF subunits.

\section{Lamprey NF180 can be enzymatically dephosphorylated with alkaline phosphatase}

After extensive enzymatic dephosphorylation with alkaline phosphatase, mammalian NF-M and NF-H migrate faster in SDS-PAGE (Julien and Mushynski, 1983; Carden et al., 1985), and $\mathrm{mAbs}$ can distinguish between the native (phosphorylated), and enzymatically dephosphorylated states of these subunits (Sternberger and Sternberger, 1983; Carden et al., 1985; Lee et al., 1987). Phosphorylation independent epitopes in mammalian NF subunits also can be defined with mAbs (Carden et al., 1985; Lee et al., 1987). The experiments described here indicate that very similar phosphorylation-dependent and -independent lamprey NF180 determinants are detected with our library of anti-rat $\mathrm{NF} \mathrm{mAbs}$, and representative data to illustrate these properties of lamprey NF180 are shown in Figure 5. After incubation with alkaline phosphatase for different lengths of time, nitrocellulose replicas of electrophoretically separated lamprey cytoskeletal proteins were probed with RMO44 (a mAb that recognizes a phosphorylation-independent epitope within the core domain of mammalian NF-M). No change or only a slight enhancement of immunoreactivity was seen (Fig. $5 A$ ). In contrast, when identical nitrocellulose replicas were probed with RMO62 (a mAb that recognizes a P[+]-type epitope on mammalian NF-M), lamprey NF180 immunoreactivity was quenched in a progressive manner; this suggests that the RMO62 gradually lost the ability to bind NF180 as phosphates were removed progressively from this subunit by longer exposures to alkaline phosphatase (Fig. $5 B$ ). These results suggest that some of the phosphate residues on lamprey NF180, like their counterparts in mammalian NF subunits, were enzymatically dephosphorylated by the enzyme alkaline phosphatase. However, many phosphate residucs in NF180 appear resistant to treatment with this enzyme since the mobility of lamprey NF180 did not accelerate in SDS-PAGE after enzyme treatment, as occurs with NF-H and NF-M of several mammalian species (Julien and Mushynski, 1983; Carden et al., 1985; Lee et al., 1987; Schmidt 


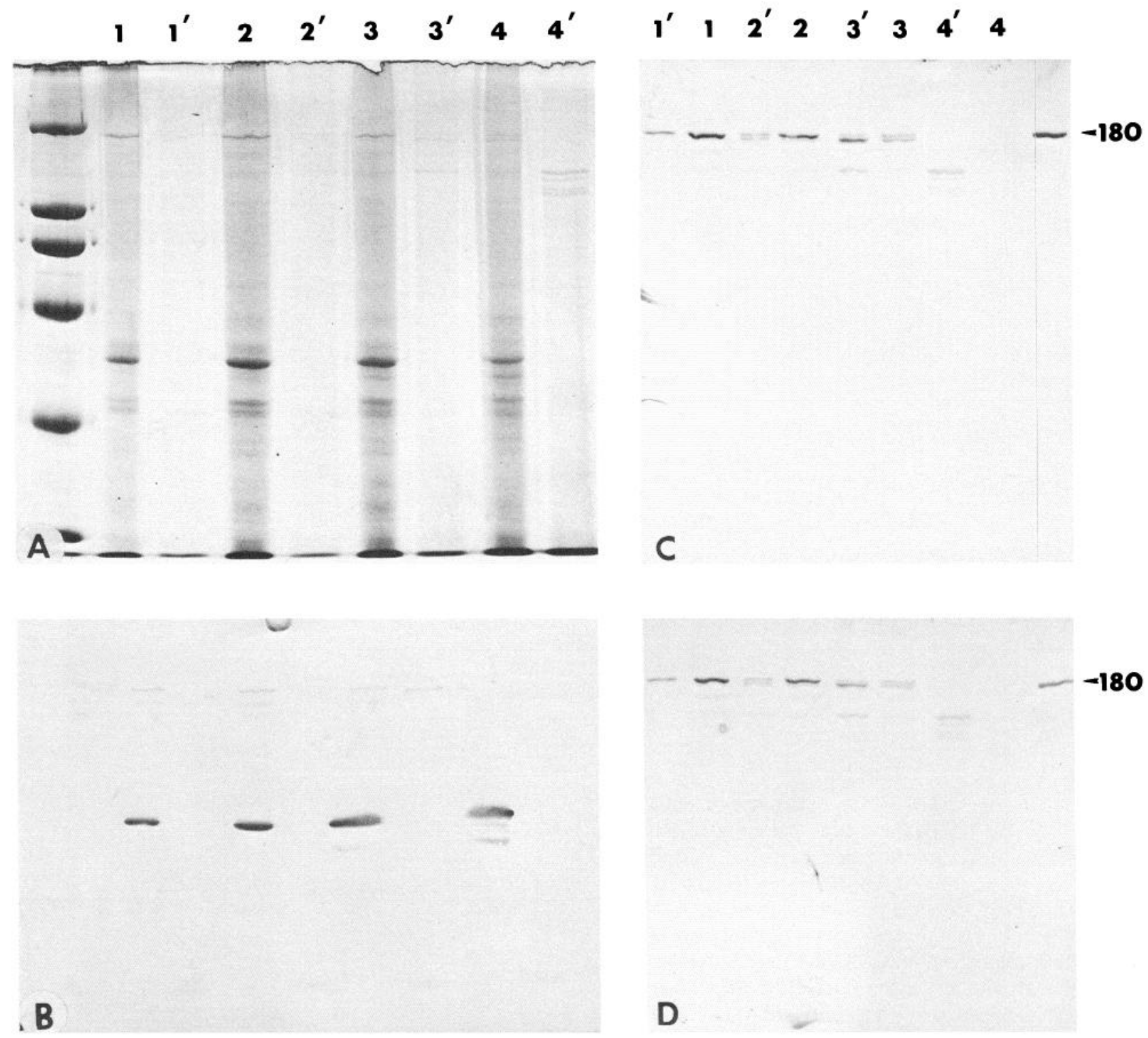

Figure 4. A, Electrophoretic (7.5\% SDS-PAGE) profile of lamprey NF180 digested with different concentrations of chymotrypsin. Molecularweight standards (same as in Fig. $1 A$ ) are shown at left. The gel in $A$ was stained with Coomasie blue, and pellets (lanes $1-4)$ or soluble products (lanes 1'-4) are revealed after digestion for $30 \mathrm{~min}$ with $0.1 \mu \mathrm{g} / \mathrm{ml}$ (lanes 1 and 1);1 $1 \mu \mathrm{g} / \mathrm{ml}$ (lanes 2 and 2); $10 \mu \mathrm{g} / \mathrm{ml}$ (lanes 3 and 3); or 100 $\mu \mathrm{g}$ / $\mathrm{ml}$ (lanes 4 and 4 ) of chymotrypsin. Note that lamprey NF180 diminishes, while lower- $M_{r}$ fragments become more abundant with increasing concentrations of chymotrypsin. In $B-D$, nitrocellulose replicas were prepared from gels identical to the one in $A$ and were then probed with mAbs (Ta56 in $B$, RMO62 in $C$, and RMO125 in $D$ ) that recognize rat NF subunits, but also cross-react with lamprey NF180. The arrowheads in $B$ and $C$ indicate the position of intact lamprey NF180. The specificities of these mAbs are described in Table 1 and are shown schematically in Figure 3 ; the results are discussed in the text.

et al., 1987). Alternatively, lamprey NF180 may contain an insufficient number of phosphates to lead to drastic changes in electrophoretic mobility after dephosphorylation.

\section{Distinct lamprey NF180 isoforms are differentially expressed in brain and spinal cord: immunoblot evidence}

Region-specific differences in the expression of lamprey NF180 isoforms were analyzed in 2-D gels stained for proteins and in 2-D gel immunoblots; representative data from these studies are shown in Figure 6. Figure 6, $A, B$, show silver-stained 2-D gels of spinal cord and brain, respectively, in which lamprey NF1 80 focuses discontinously within a $\mathrm{p} I$ range (5.2-8.1) that is similar to mammalian NF-H (Oblinger, 1987). Note that the spinal cord profile (Fig. 6A) showed a large intense streak at $M_{r}$ $180 \mathrm{kDa}$ at the acidic end (brackets) and another spot with a lower $M_{r}(170 \mathrm{kDa})$ at the basic end (see arrows). The gels of the brain homogenate (Fig. $6 \mathrm{~B}$ ) differed somewhat from those of spinal cord in that the acidic streak was comparatively less intense while the basic spot was more intense. These differences in the relative amounts of acidic and basic NF180 isoforms in spinal cord versus brain most likely reflect region-specific differences in NF180 isoform expression. They are unlikely to be artifacts due to variations in the amount of protein loaded onto the gels because many other spots in the 2-D gels of brain and spinal cord (see arrowheads) exhibit similar staining intensity in both preparations. 


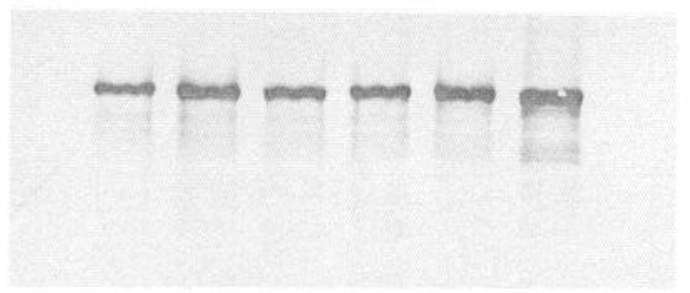

RMO 44

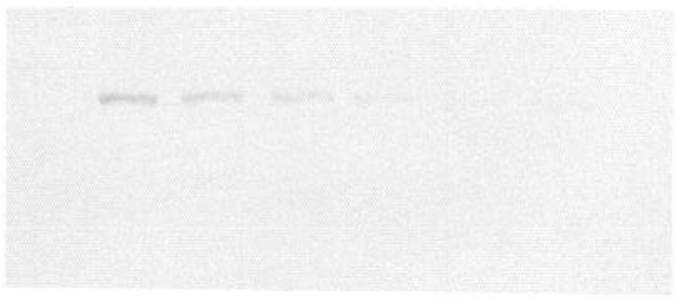

RMO 62

Figure 5. Nitrocellulose replicas of $7.5 \%$ gels containing lamprey NF enriched fractions were treated with alkaline phosphatase for progressively longer periods of time before being loaded into separate wells for electrophoresis. The incubation times for each of the 6 preparations shown here from left to right: 0-time (untreated), $12 \mathrm{~min}, 36 \mathrm{~min}, 108$ $\mathrm{min}, 324 \mathrm{~min}$, and $18 \mathrm{hr}$. Upper panel was probed with RMO44, which is $\mathrm{P}[$ ind], while lower $B$ was probed with RMO62, which is $\mathrm{P}[+]$. Both mAbs bind only lamprey NF180. Further details on the specificities of these $\mathrm{mAbs}$ are listed in Table 1 and shown schematically in Figure 3.

The notion that these differences in brain versus spinal cord NF1 80 are due to phosphorylation was suggested by additional 2-D immunoblots of spinal cord homogenates similar to those just described. For example, mAb (RMO44) specific for core epitopes in rat NF-M detected both the large acidic and the small basic spots (Fig. 6C). In contrast, immunoblots of similar 2-D gels of brain homogenates revealed only the smaller basic spot when probed with the same mAb (Fig. 6D). Since core determinants are unaffected by phosphorylation state, and since phosphorylation shifts the $\mathrm{p} I$ of rat NF-H and NF-M from acidic to basic (Lee et al., 1987), these 2-D immunoblots most likely reflect the presence of lower amounts of the acidic, phosphorylated isoforms of NF180 in brain relative to spinal cord, where they appear to be more abundant. In support of these interpretations, a mAb specific for a phosphorylation-specific epitope in rat NF-M (RMO62) did not immunostain nitrocellulose replicas of brain (data not shown), but it detected only the large acidic streak and not the small basic spot in nitrocellulose replicas of lamprey spinal cord 2-D gels (Fig. 6E). Thus, these data provide further evidence that the lamprey NF180 variants described here are expressed in unequal amounts or ratios in the different populations of axons and neurons included in brain versus spinal cord homogenates of the lamprey CNS.

Figure 6. $A$ and $B, 2$-dimensional gel profile of lamprey NF180 in spinal cord and brain, respectively. Selected areas of the silver-stained gels are shown; equal amounts of lamprey spinal cord and brain homogenates were used for each gel. $C-E$, Selected areas of blots produced using nitrocellulose replicas of 2-dimensional gels similar to those seen in $A$ and $B$. Panel $C$ contains a spinal cord preparation, while $D$ contains a brain preparation; both replicas were stained with RMO44. The spinal
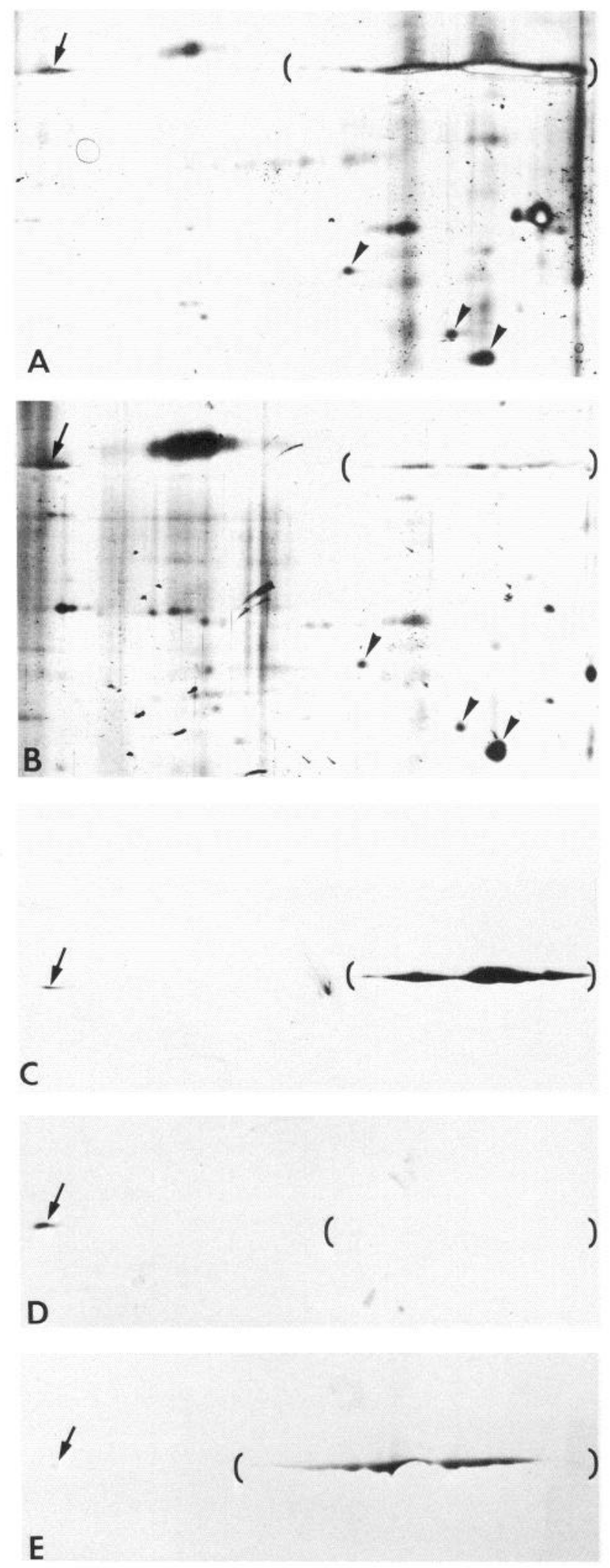

cord preparation shown in $E$ was stained with RMO62. In $A-E$, the arrows indicate the position of nonphosphorylated lamprey NF180 and brackets show the position of phosphorylated NF180. Note that nonphosphorylated isoform of NF1 80 migrates slightly ahead of the highly acidic phosphorylated forms. The arrowheads indicate other spots that were used to align the positions of the NF1 80 isoforms; they are equally intense in both $A$ and $B$. 

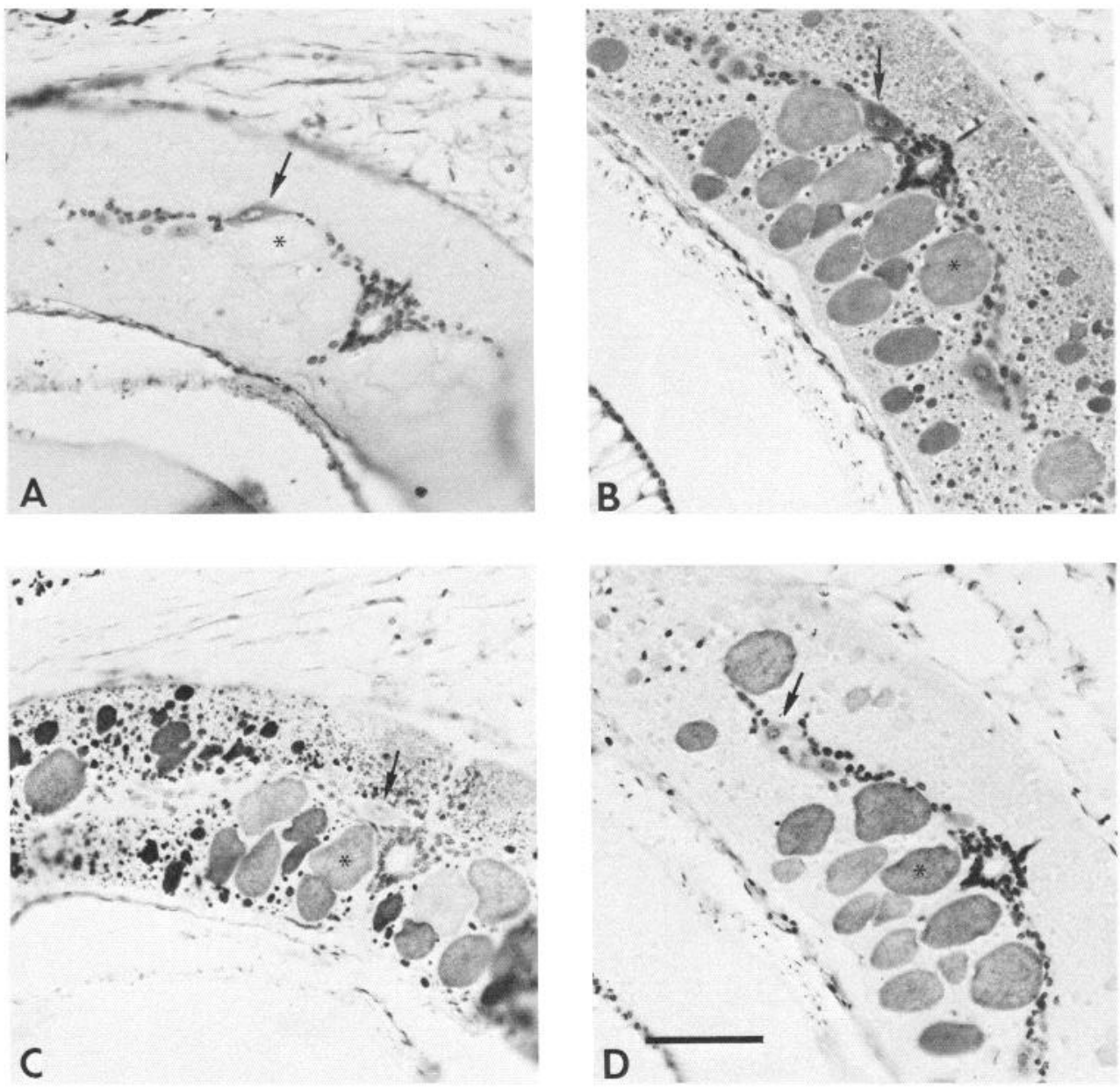

Figure 7. The different immunohistochemical staining patterns achieved in paraffin sections of Bouin's-fixed lamprey spinal cord using 4 different mAbs (RMO14 in $A$; RMO308 in $B$; RMO62 in $C$; RMO34 in $D$ ) with specificities for different phospho-isoforms of lamprey NF180. The mAb specificities are described in Table 1 and shown schematically in Figure 3. The sections are cut transverse to the long axis of the spinal cord with the spinal canal visible to the right of center. Large-diameter axons (asterisks) are prominently stained in $C$ and $D$, small-diameter axons are stained as well in $B$ and $C$, while NF-negative and -positive neurons are identified with arrows in $A-D$. The sections were counterstained with hematoxylin. Scale bar, $100 \mu \mathrm{m}$.

\section{Immunohistochemistry demonstrates a dramatic compartmentalization of lamprey NF180 isoforms within different regions of individual lamprey neurons}

The nonuniform distribution of the different NF180 isoforms in homogenates of brain versus spinal cord correlated immunohistochemically with a pronounced segregation of these NF180 variants into architecturally distinct domains of individual lamprey neurons at the light microscopic level. Figures 7 and 8 illustrate this in sections of lamprey spinal cord and brain probed with mAbs specific for several different NF180 isoforms (see Table 1 and Fig. 3). For example, a core-specific mAb (RMO14) selectively stained perikarya and dendrites of spinal cord neurons while adjacent axons in the same section were completely negative (Fig. $7 A$ ). In sections of lamprey brain, this $\mathrm{mAb}$ stained only the giant Muller cell bodies and dendrites (Fig. $8 \mathrm{~A}$ ), and it is from these same giant Muller cells that the large unstained axons in spinal cord arise. The lack of staining by core-specific mAbs in axons may be due to the masking of core epitopes when NF180 subunits are assembled into filaments and/or phosphorylated after exiting the cell body. A staining pattern similar to that seen with RMO14 (neurons and dendrites positive, axons negative) was observed in brain sections probed with a mAb (RMdO15) specific for the dephosphorylated sequence KSP(V/ A) (Fig. $8 D$, Table 1, and Fig. 3). Thus, KSP(V/A) may be a NF1 80 phosphorylation site that is phosphorylated by a kinase at the axon hillock as the nascent, or nonphosphorylated NFs exit the perikaryon and enter the axon. This could account for the extinction of NF180 binding by this mAb in the axonal domain of these neurons (data not shown).

In contrast to the highly compartmentalized distribution of NF180 epitopes recognized by our $\mathrm{P}[-] \mathrm{mAbs}$ and $\mathrm{P}[\mathrm{ind}]$ anticore mAbs (neurons and dendrites positive, axons negative), neuronal cell bodies, dendrites, and axons in both spinal cord and brain were immunostained by a mAb (RMO308) specific for a $\mathrm{P}$ [ind] determinant located in the sidearm of NF180 (Figs. $7 B$ and $8 B, 3$, and Table 1 ). This $\mathrm{mAb}$ is known to bind multiphosphorylation repeats located in the sidearm of human NF-M (Lee et al., 1988a). Sequential sections stained with RMO308 or RMO14 illustrate the contrasting staining patterns noted here (Figs. $8 A$ and $8 B$ ). The same axons can be identified in these sequential sections, and they are alternatively positive with RMO308 or negative with RMO14, which suggests that structural changes due to phosphorylation affect the immunological properties of lamprey NF180 as it is translocated from perikarya to axons. Further evidence for this is seen in Figures $7 C$ and $8 C$, where spinal cord and brain sections have been immunostained with RMO62, a $\mathrm{P}[+] \mathrm{mAb}$ (Table 1 and Fig. 3). This mAb selectively stains spinal cord axons but not neuronal cell bodies (Fig. $7 \mathrm{C}$ ). In brain sections, only small axons were stained by this $\mathrm{mAb}$ while giant cell bodies remained negative (Fig. $8 C$ ). Furthermore, when spinal cord sections were treated with alkaline phosphatase prior to probing with RMO62, the immunoreactivity was greatly diminished, whereas no change 

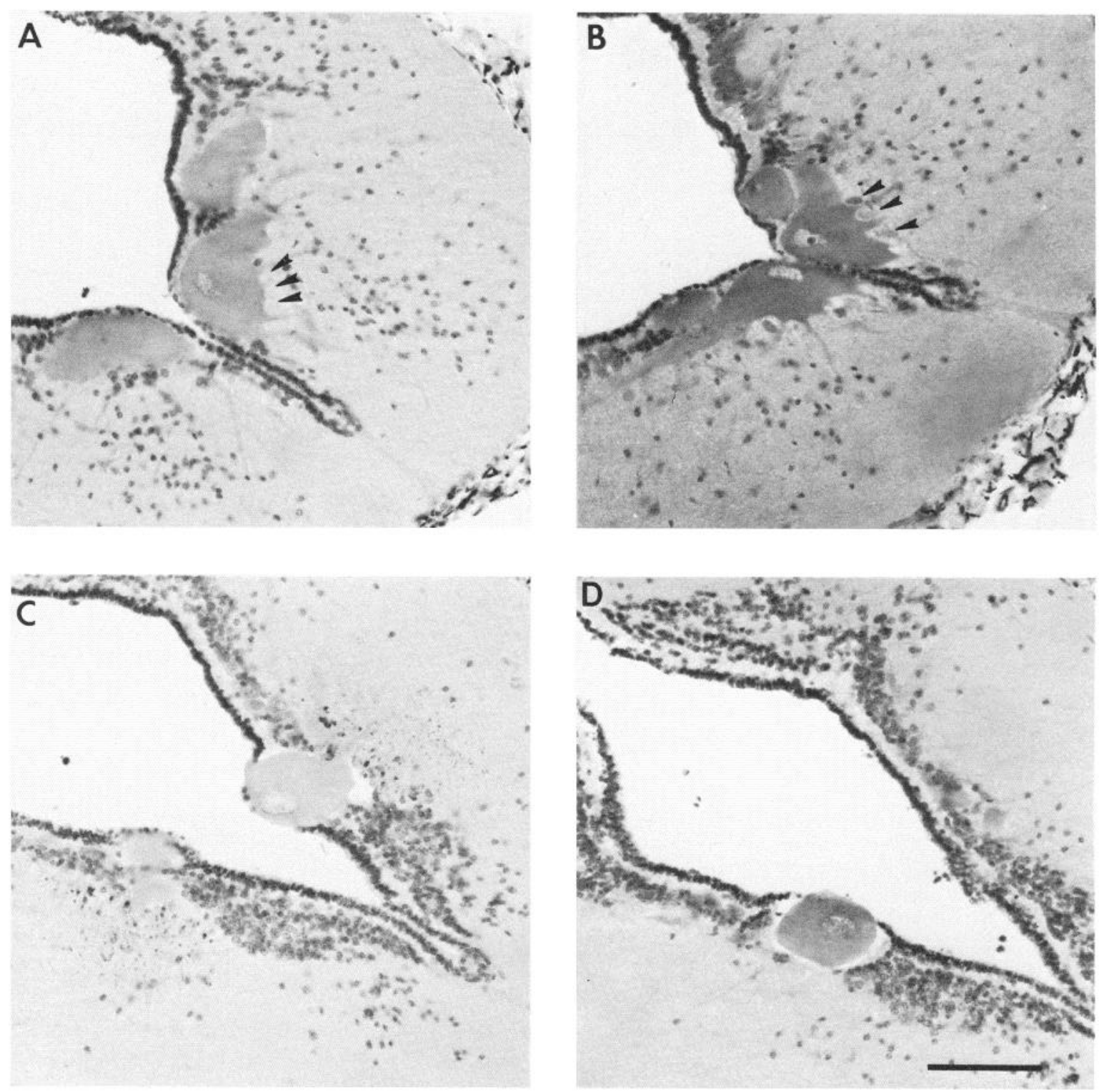

Figure 8. Immunohistochemical results from lamprey brain achieved with the following mAbs: RMO14 $(A)$, RMO308 $(B)$, RMO62 $(C)$, and RMdO15 $(D)$. The sections were prepared as in Figure 6; the specificities of the mAbs are listed in Table 1 and shown schematically in Figure 3. The arrowheads show the positions of 3 axons that were stained with RMO308 but not with RMO14. Scale bar, $100 \mu \mathrm{m}$.

in such activity was observed when similar tissue sections were treated with alkaline phosphatase prior to probing them with a phosphate-independent mAb such as RMO14 (data not shown).

Finally, Figure $7 D$ shows a spinal cord section stained with RMO34, a P $[+++] \mathrm{mAb}$ that is specific for an epitope on the multiphosphorylation repeat domain of rat NF-H (Lee et al., 1988b; see also Table 1 and Fig. 3). This mAb, like RMO62, did not stain neuronal perikarya, but unlike RMO62, it only stained the very large axons in lamprey spinal cord. Remarkably, small spinal cord axons were virtually negative with this $\mathrm{mAb}$, which suggests that certain NF180 phosphorylation sites are selectively occupied only in large-diameter axons. As might be predicted from immunoblot data on RMO34, when spinal cord sections were incubated even in low concentrations (10 units/ $\mathrm{ml}$ ) of alkaline phosphatase, this was sufficient to completely abolish all RMO34 immunoreactivity (data not shown).

\section{Discussion}

Although lamprey axons contain 10-nm-diameter filaments morphologically indistinguishable from mammalian NFs, the biochemical and immunological evidence provided here revealed that lamprey NF180 contains many structural features of all 3 mammalian NF subunits including a Triton-X-insoluble $40 \mathrm{kDa}$ core unit containing epitopes similar to those that are unique to the core domain of each of the 3 NF subunits; a 140 $\mathrm{kDa}$ peripheral domain containing multiple phosphorylationdependent epitopes, as well as several phosphorylation-independent epitopes; a region in the NF180 peripheral domain immunologically similar to the multiphosphorylation repeats in mammalian NF-H and NF-M; an epitope recognized by the anti-IFA $\mathrm{mAb}$; and an absence of epitopes recognized by several mAbs specific for the IF subunits of non-neuronal cells. Despite 
these extensive similarities, lamprey NF 180 differs significantly from each of the mammalian NF triplet proteins. Only a limited number of monoclonals in our library of mAbs raised to mammalian NF proteins cross-reacted with lamprey NF180. For example, only 11 of $114 \mathrm{mAbs}$, which recognize multiphosphorylation repeats in human NF-M and/or rat NF-H, cross-

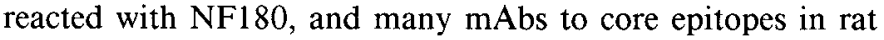
NF-L and NF-M failed to bind to lamprey NF180. Further, despite the large number of phosphorylation-dependent mAbs in our library, we did not identify in lamprey the equivalent of the intermediate phospho-isoform (i.e., $\mathrm{P}[++]$ ) of rat NF-H or NF-M. This may reflect specialized functions that are subserved by NFs only in highly developed species, such as mammals. Another dramatic difference between lamprey NF 180 and mammalian NF subunits, which exist in a variety of phospho-isoforms that partially overlap in their distribution within asymmetrical mammalian neurons (Bennett and DiLullo, 1985; Lee et al., 1986b, 1987; Sternberger and Sternberger, 1983; Schmidt et al., 1987), is the observation that some lamprey NF180 isoforms are rigidly segregated into nonoverlapping regions of neurons. For example, both $\mathrm{P}[-]$ and $\mathrm{P}[$ ind]-core epitopes were detected exclusively in neuronal perikarya, while both $\mathrm{P}[+]$ and $\mathrm{P}[+++]$ isoforms were found only in axons. Finally, although specific phospho-isoforms of lamprey NF180 were present in axons of all sizes, other NF180 phospho-isoforms were found only in large-diameter axons. For these reasons, studies of lamprey NF180 should facilitate analyses of the functional significance of NF peripheral domains in general and the phosphorylation of these domains in particular.

Since many vertebrate and invertebrate species display neuron-specific IF proteins that share epitopes with mammalian NFs (Lee et al., 1986a, 1988a, b) and have an affinity for silver stains like mammalian NFs (Phillips et al., 1983), it is assumed that NFs evolved as a specialized form of neuron-specific IFs prior to the divergence of vertebrates and invertebrates about 800 million years ago (Lasek et al., 1985). Based on an extensive survey of the NFs of diverse vertebrate and invertebrate species, Lasek and coworkers have proposed that the predecessor of all NF subunits emerged as a result of a duplication of the ancestral IF gene that resulted in a new low- $M_{r}$ (approximately $60 \mathrm{kDa}$ ) IF protein with the typical IF rod domain. Since NF proteins, like a number of other gene products, are expressed only in neurons, it also was proposed that early in evolution, the original NF precursor gene must have become linked to a neuron-specific genetic regulatory locus. Following the initial appearance of this neuron-specific IF gene, mutations in the region encoding the carboxy-terminal tail probably would have led to the development of the specialized peripheral domain. It has also been suggested that the higher- $M_{r}$ NF subunits may have evolved by the addition of genetic sequences (i.e., exons separated by a number of introns) to the sidearm or carboxy-terminal domain of the predecessor NF gene. The insertion or deletion of these exons would account for variations in the size of the low-, middle-, and high- $M_{r}$ mammalian NF subunits.

The data on lamprey NF180 we have presented here, together with our work on the multiphosphorylation repeat sites in mammalian NF-H and NF-M (Lee et al., 1988a, b), lead us to extend and to modify the proposal of Lasek et al. (1985). Whilc the initial duplication event may have produced a small (approximately $60 \mathrm{kDa}$ ) "precursor" NF, we believe that this protein could not subserve the specialized functions of a true NF until it acquired some of the features found in all NFs so far described.
Therefore, we suggest that the primordial vertebrate NF gene, encoding the first functional NF protein, produced a fairly large ( $>130 \mathrm{kDa}$ ) polypeptide that containcd 2 fundamental NF clements: (1) an obligatory core or $\alpha$-helical coiled-coil domain capable of self-assembly into $10 \mathrm{~nm}$ filaments and (2) a peripheral, highly negatively charged sidearm extending from the core domain towards the carboxy-terminus, within which resides multiple phosphorylation sites capable of mediating essential, dynamic NF functions. A second duplication of this archetypal NF gene in the vertebrate lineage probably occured after the lamprey evolved, but before the divergence of amphibians from fish, because all of these vertebrates have an additional low- $M_{r}$ NF subunit (see Lasek et al., 1985). A third gene duplication may have occurred more recently (200-400 million years ago). This would account for the presence of the third high- $M_{r}$ NF subunit in most amphibians, birds, and mammals.

Our biochemical and immunologic data support these hypotheses by showing that NF180 combines several structural motifs of mammalian NFs and also allows us to speculate as to which of these features are strictly necessary for NF function. In addition, the specific localization of phosphorylated isoforms of NF180 allows us to propose possible functions for these multiple phosphorylation sites. The mAbs that recognized all lamprey axons regardless of diameter by immunohistochemistry (i.e., $P[+]$ ) were specific for mammalian NF-M, but none of them cross-reacted with the multiphosphorylation repeat domains of the 2 large mammalian NF subunits. In contrast, the $\mathrm{mAbs}$ that recognized selectively large-diameter axons (i.e., $\mathrm{P}[+++]$ ) were specific for mammalian NF-H and also recognized the multiphosphorylation tandem repeats in NF-H. The class of phosphorylation sites recognized by the former group of mAbs may subserve a purely structural role in lamprey axons as obligatory phosphorylation sites, perhaps for the stabilization of assembled NFs, while the class of phosphorylation sites recognized by the latter group of mAbs may subserve a more dynamic role in the regulation of axonal caliber, and perhaps in axonal transport and/or in interactions among NFs and other axonal organelles. Furthermore, the presence of 2 different phospho-isoforms in different axonal populations suggests that more than one kinase may be involved in the phosphorylation of NF180: one distributed throughout all axons and another confined to or activated in large-diameter axons only. Multiple kinases have been reported to phosphorylate mammalian NF proteins (I eterrier et al., 1982; Pant et al., 1986; Toru-Delbauffe et al., 1986), but their precise role in the biology of NFs remains to be elucidated.

As more is understood about the functions of NFs, it becomes clear that these functions are intimately associated with its abilities to self-assemble into filaments and to undergo cyclic phosphorylation/dephosphorylation (Nixon et al., 1987). The first property is common to all IF proteins, but the second is NF specific. We propose, therefore, that the first NF proteins must have been of high $M_{r}$ with multiphosphorylation domains on their carboxy-sidearm extensions. Lamprey NF180 fulfills these criteria, and we postulate that it is the single ancestor of the mammalian NF polypeptides based on the strength of its immunological and biochemical relatedness to the NF triplet and on the fact that lamprey is the lowest known vertebrate (Hardisty, 1982).

Based on the available sequence and other data, we propose that of all 3 mammalian NF subunits, NF-M is most closely related to NF180. The evidence for a close relationship of NF180 
to mammalian and nonmammalian high- $M_{r}$ subunits in general and NF-M in particular include (1) the single NF polypetide in lamprey and Myxicola are large (180 and $160 \mathrm{kDa}$, respectively), and both contain an $\alpha$-helical coiled-coil core domain and a highly charged, extended peripheral sidearm that is replete with phosphates (Eagles et al., 1981; Lee et al., 1988a); (2) all other vertebrate and invertebrate species examined to date (Aplysia may be an exception) possess one or more high- $M_{r}(130-200$ $\mathrm{kDa}$ ) subunits, in addition to a low- $M_{r}$ NF subunit; (3) a multiphosphorylation repeat region appears to exist in diverse phyla, since many of our mAbs that bind the multiphosphorylation tandem repeats of human NF-M and/or rat NF-H also crossreact with the higher- $M_{r}$ NF subunits of chicken (avian), Xenopus (amphibian), lamprey (cyclostome), Myxicola (annelid), squid (mollusc), and all mammalian species (e.g., human, rat, cow, mouse, hamster) examined to date (Lee et al., 1988a, b); (4) genomic or cDNA sequence information available to date on NF subunit proteins from both mammals and birds reveals the presence of a multiphosphorylation repeat in the peripheral domain, containing at least one or more units of the amino acid sequence KSP (Robinson et al., 1986; Levy et al., 1987; Myers et al., 1987; Napolitano et al., 1987; Lopfs et al., 1987); (5) available information on the genomic DNA structure of mammalian NF subunits revcals that human and mousc NF-M have 2 introns (Levy et al., 1987; Myers et al., 1987), mouse NF-L has 3 introns (Lewis and Cowan, 1986), and human NF-H also has 3 introns (Lees et al., 1988). Furthermore, 2 of the 3 introns in mouse NF-L and human NF-H coincide exactly with the 2 introns found in human and mouse NF-M. Taken together, these observations suggest that NF-M is the descendant of the oldest vertebrate NF gene within a model of continued accretion of introns after an original RNA-mediated transposition. Further evidence as to NF180's relationship to NF-M and as to whether NF evolved via RNA-mediated or exon-shuffling events must await sequence and gene structure data on the lamprey NF180 gene.

If NF proteins evolved along with the emergence of an advanced nervous system in complex metazoa, then the earliest function subserved by NFs may have been the maintenance of axon volume and the regulation of axon diameter. The archetypal NF polypeptide therefore would have to be capable of assembling into filaments, and assembled NFs would have to be present in a prescribed density throughout the length of the axon. The long sidearms of this archetypal NF subunit may have played a central role in this earliest NF function by regulating NF packing density. This could be accomplished by the addition of phosphates to the multiphosphorylation repeat, which would result in the extension of the sidearms from the NF core as a consequence of repulsive charge-charge interactions. Although we have discussed data that lend credence to this speculation, we expect that lamprey NF180 may provide an effective model system in which to marshal additional evidence to prove or disprove our thesis.

\section{References}

Bartnik, E., K. Kossmagk-Stephan, and K. Weber (1987) Evidence for two intermediate filament prototypes in the invertebrate Myxicola; neurofilaments and non-neuronal intermediate filaments differ in subunit size and immunological properties. Eur. J. Cell Biol. 44: 219228.

Bennett, G. S., and C. DiLullo (1985) Slow posttranslational modification of a neurofilament protein. J. Cell Biol. 100: 1799-1804.

Carden, M. J., W. W. Schlaepfer, and V. M.-Y. Lee (1985) The struc- ture, biochemical properties, and immunogenicity of neurofilament peripheral regions are determined by phosphorylation state. J. Biol. Chem. 260: 9805-9817.

Carden, M. J., J. Q. Trojanowski, W. W. Schlaepfer, and V. M.-Y. Lee (1987) Two-stage expression of neurofilament polypeptides during rat neurogenesis with early establishment of adult phosphorylation patterns. J. Neurosci. 7: 3489-3504.

Chin, T. K., P. A. M. Eagles, and A. Maggs (1983) The proteolytic digestion of ox neurofilaments with trypsin and -chymotrypsin. Biochem. J. 215: 239-252.

Cohen, R. S., H. C. Pant, S. House, and H. Gainer (1987) Biochemical and immunocytochemical characterization and distribution of phosphorylated and nonphosphorylated subunits of neurofilaments in squid giant axon and stellate ganglion. J. Neurosci. 7: 2056-2074.

Eagles, P. A. M., D. S. Gilbert, and A. Maggs (1981) The location of phosphorylation sites and $\mathrm{Ca}^{2+}$-dependent proteolytic cleavage sites on the major neurofilament polypeptides from Myxicola infundibulum. Biochem. J. 199: 101-111.

Friede, R. L., and T. Samorajski (1970) Axon caliber related to neurofilaments and microtubules in sciatic nerve fibers of rats and mice. Anat. Rec. 167: 379-387.

Geisler, N., E. Kaufman, S. Fischer, U. Plessmann, and K. Weber (1983) Neurofilament architecture combines structural principles of intermediate filaments with carboxy-terminal extensions increasing in size between triplet proteins. EMBO J. 2: 1295-1302.

Geisler, N., J. Vandekerckhove, and K. Weber (1987) Location and sequence characterization of the major phosphorylation sites of the high molecular mass neurofilament proteins $M$ and $H$. FEBS Lett. 221: $403-407$

Hardisty, M. W. (1982) Lampreys and hagfishes: Analysis of cyclostome relationships. In The Biology of Lampreys, M. W. Hardisty and I. C. Potter, eds., pp. 165-259, Academic, New York.

Hoffman, P. N., J. W. Griffin, and D. L. Price (1984) Control of axonal caliber by neurofilament transport. J. Cell. Biol. 99: 705-714.

Hoffman, P. N., D. W. Cleveland, J. W. Griffin, P. W. Landes, N. J. Cowan, and D. L. Price (1987) Neurofilament gene expression: A major determinant of axonal caliber. Proc. Natl. Acad. Sci. USA 84: 3472-3476.

Julien, J.-P., and W. E. Mushynski (1982) Multiple phosphorylation sites in mammalian neurofilament polypeptides. J. Biol. Chem. 257: $10467-10470$

Julien, J.-P., and W. E. Mushynski (1983) The distribution of phosphorylation sites among identified proteolytic fragments of mammalian neurofilaments. J. Biol. Chem. 258: 4019-4025.

Laemmli, U.-K. (1970) Cleavage of structural proteins during the assembly of the head of bacteriophage T4. Nature 227:680-685.

Lasek, R. J., L. Phillips, M. J. Katz, and L. Autilio-Gambetti (1985) Function and evolution of neurofilament proteins. Ann. NY Acad. Sci. 455: 462-478.

Lee, V. M.-Y., C. D. Page, H.-L. Wu, and W. W. Schlaepfer (1984) Monoclonal antibodies to gel excised glial filament protein and their reactivity with other intermediate filaments. J. Neurochem. 42: $25-$ 32.

Lee, V. M.-Y., M. J. Carden, and W. W. Schlaepfer (1986a) Structural similarities and differences between neurofilament proteins from five different species as revealed using monoclonal antibodies. J. Neurosci. 6: 2179-2186.

Lee, V. M.-Y., M. J. Carden, and J. Q. Trojanowski (1986b) Novel monoclonal antibodies provide evidence for the in situ existence of a non-phosphorylated form of the largest neurofilament subunit. J. Neurosci. 6: 850-858.

Lee, V. M.-Y., M. J. Carden, W. W. Schlaepfer, and J. Q. Trojanowski (1987) Monoclonal antibodies distinguish several differentially phosphorylated states of the two largest rat neurofilament subunits (NF-H and NF-M) and demonstrate their existence in the normal nervous system of adult rat. J. Neurosci. 7: 3474-3488.

Lee, V. M.-Y., L. Otvos, M. J. Carden, M. Hollosi, B. Dietzschold, and R. A. Lazzarini (1988a) Identification of the major multi-phosphorylation site in mammalian neurofilaments. Proc. Natl. Acad. Sci. USA 85: 1998-2002.

Lec, V. M.-Y., L. Otvos, Jr., M. L. Schmidt, and J. Q. Trojanowski (1988b) Alzheimer's neurofibrillary tangles share immunological homologies with multiphosphorylation domains in normal neuronal cytoskeletal proteins. Proc. Natl. Acad. Sci. USA (in press).

Lees, J. F., P. S. Shneidman, S. F. Skuntz, M. J. Carden, and R. A. 
Lazzarini (1988) The gene structure of the largest human neurofilament subunit (NF-H) predicts a protein with multiple repeated sites for in vivo phosphorylation. EMBO J. 7: 1947-1955.

Leterrier, J.-F., R. K. H. Liem, and M. L. Shelanski (1982) Preferential phosphorylation of the 150,000 molecular weight component of neurofilaments by a cyclic-dependent microtubule-associated protein $\mathrm{ki}$ nase. J. Cell. Biol. 90:755-760.

Levy, E., R. K. H. Liem., P. D'Eustachio, and N. J. Cowan (1987) Structure and evolutionary origin of the gene encoding mouse NF$\mathrm{M}$, the middle molecular-mass neurofilament protein. Eur. J. Biochem. 166: 71-77.

Lewis, S. A., and N. J. Cowan (1986) Anomalous placement of introns in a member of the intermediate filament multigene family: An evolutionary conundrum. Mol. Cell. Biol. 6: 1529-1534.

Magin, T. M., M. Hatzfeld, and W. W. Franke (1987) Analysis of cytokeratin domain by cloning and expression of intact and deleted polypeptide in Escherichia coli. EMBO J. 6: 2607-2615.

Myers, M. W., K. A. Lazzarini, V. M.-Y. Lee, W. W. Schlaepfer, and D. L. Nelson (1987) The human mid-size neurofilament subunit: A repeated protein sequence and the relationship of its gene to the intermediate filament gene family. EMBO J. 6: 1617-1626.

Napolitano, E. W., S. S. M. Chin, D. R. Colman, and R. K. H. Liem (1987) Complete amino acid sequence and in vitro expression of rat NF-M, the middle molecular weight neurofilament protein. J. Neurosci. 7: 2590-2599.

Nixon, R. A., S. E. Lewis, and L. A. Marotta (1987) Posttranslational modification of neurofilament proteins by phosphate during axoplasmic transport in retinal ganglion cell neurons. J. Neurosci. 7 : 1145-1158.

Oblinger, M. M. (1987) Characterization of posttranslational processing of the mammalian high-molecular-neurofilament protein in vivo. J. Neurosci. 7: 2510-2521.

Pant, H. C., P. E. Gallant, and H. Gainer (1986) Characterization of a cyclic nucleotide- and calcium-independent neurofilament protein kinase activity in axoplasm from squid giant axon. J. Biol. Chem. 261: 2968-2977.
Peters, A., S. L. Palay, and H. De F. Webster (1976) The Fine Structure of the Nervous System: The Neurons and Supporting Cells, Saunders, Philadelphia.

Phillips, L. L., L. Autilio-Gambetti, and R. J. Lasek (1983) Bodian's silver method reveals molecular variation in the evolution of neurofilaments. Brain Res. 278: 219-223.

Pleasure, S. J., V. M.-Y. Lee, and M. E. Selzer (1986) Neurofilament immunoreactivity in the spinal cord of the lamprey. Soc. Neurosci. Abstr. 12: 44.8 .

Pruss, R. M., R. Mirsky, M. C. Raff, R. Thorpe, A. J. Dowding, and R. H. Anderton (1981) All classes of intermediate filaments share a common antigenic determinant defined by a monoclonal antibody. Cell 27: 419-428.

Robinson, P. A., D. Wion, and B. H. Anderton (1986) Isolation of a cDNA for the rat heavy neurofilament polypeptide (NF-H). FEBS Lett. 209: 203-205.

Rovainen, C. M. (1979) Neurobiology of lampreys. Physiol. Rev. 59: 1007-107\%

Schlaepfer, W. W. (1987) Neurofilaments: Structure, metabolism, and implications in disease. J. Neuropathol. Exp. Neurol. 46: 117-129.

Schmidt, M. L., M. J. Carden, V. M.-Y. Lee, and J. Q. Trojanowski (1987) Phosphate dependent and independent neurofilament epitopes in the axonal swellings of patients with motor neuron disease and controls. Lab. Invest. 56: 282-294.

Steinert, P. M., A. C. Steven, and D. R. Roop (1985) The molecular biology of the intermediate filaments. Cell 42: 411-419.

Sternberger, L. A., and N. H. Sternberger (1983) Monoclonal antibodies distinguish phosphorylated and nonphosphorylated forms of neurofilaments in situ. Proc. Natl. Acad. Sci. USA 80: 6126-6130.

Toru-Delbauffe, D., M. Pierre, J. Osty, F. Chantoux, and J. Francon (1986) Properties of neurofilament protein kinase. Biochem. J. 235: 283-289.

Zopfs, D., I. Herman-Borgmeyer, E. D. Gundelfinger, and H. Betz (1987) Identification of gene product expressed in developing chick visual system: Characterization of the middle mol wt NF cDNA. Genes Dev. 1: 699-708. 